\title{
Pontes conceituais: uma sequência didática para o Eletromagnetismo no Ensino Médio como proposta de introdução à Física Moderna
}

Conceptual bridges: a didactic sequence for teaching Electromagnetism in High School as a proposal to introduce Modern Physics

\author{
Marcello Ferreira, Olavo Leopoldino da Silva Filho, Israel Marinho \\ Araújo, Margarida Irene da Rocha de Meneses, Helena Célia de \\ SOUZA SACERDOTE
}

Universidade de Brasília - UnB

\begin{abstract}
Resumo
São encontradas, notadamente na área de Pesquisa em Ensino de Física, investigações acerca das possibilidades e das dificuldades de inclusão dos tópicos de física do século XX (em diante) no Ensino Médio brasileiro. Essas investigações se dão, no entanto, em ritmo cadenciado, mormente defendendo sua necessidade e, às vezes, propondo abordagens pontuais. Entretanto, o que a literatura também indica é que parece distante termos a física Moderna e Contemporânea (FMC) como parte significativa dos programas e currículos escolares. O presente texto intenta discutir bases teóricas de aprendizagens por meio da Teoria dos Campos Conceituais de Vergnaud, com o intuito de defender de maneira sistêmica a possibilidade de que os elementos histórico-filosóficos da ciência (e da física) possam deixar de figurar como contextualizadores, complementos ou adereços, para assumir uma posição de matriz estruturante de um plano de curso ou currículo, capaz de dar significado aos campos mais avançados da física. Como exemplo disso, descrevemos um produto educacional experimental (sequência didática) destinado à aplicação no Ensino Básico, com vistas a dar significado ao Eletromagnetismo pela compreensão das Equações de Maxwell por um viés histórico-fenomenológico. O presente trabalho constatou, após a aplicação da sequência didática, que um dos maiores problemas em abordar a FMC é a falta de construção de uma narrativa única, que respeite os conflitos metafísicos, ontológicos e epistemológicos desse saber. Critica-se, assim, o currículo tradicional por, em geral, segmentar os ramos da física e, assim, dificultar estruturalmente qualquer tentativa pedagógica de temas que só foram desenvolvidos originalmente pela unificação ou superação de uma visão de mundo.
\end{abstract}

Palavras-chave: Campos conceituais. Eletromagnetismo. Física Moderna.

\footnotetext{
*marcellof@unb.br
} 


\begin{abstract}
In the research field of physics teaching there are a wide literature regarding the possibilities and obstacles to include topics of XXth Century physics (and beyond) in brazilian High School. However, these researches are disperse, generally sustaining just their own approach and, sometimes, proposing only specific approaches.Thus, the literature indicates that we seem far from having modern and contemporaneous physics (MCP) as a meaningful part of the curricula. The present work deals with the theoretical bases of learning using the Conceptual Field Theory of Vergnaud, as a means do sustain, in a systemic way, the possibility that historical and philosophical elements of Science (and of physics) can begin to play a structrual role in planning a course or in the curriculum, instead of working just as a context for teaching disciplines, thus giving meaning to more advanced areas of physics. As a concrete example of these ideas, we presesnt an experimental instructional product (didactic sequence) using the teaching of Electromagnetism by means of Maxwell's equations from a historical and phenomenological approach. We found, after the application of the didactic sequence, that one of the major problems in addressing MCP comes from the absence of a unified narrative, which does not bypass the metaphysical, ontological and epistemological conflicts of the field. We thus criticize the traditional curriculum for, in general, segment the various fields of physics and, thus, make it structurally more difficult whichever pedagogical trial to teach topics that were originally developed by the unification or superation of one worldview.
\end{abstract}

Keywords: Conceptual fields. Electromagnetism. Modern physics.

\title{
I. INTRODUÇÃO
}

A discussão acerca dos motivos, das possibilidades e das dificuldades da inserção de conteúdos e temas de Física Moderna e Contemporânea (FMC) no Ensino Básico brasileiro é corrente na área de pesquisa em Ensino de Física. Podemos citar como exemplos de trabalhos que cercam essa temática, Terrazzan (1992) e Ostermann e Moreira (2000) que expõem a problemática e revisam algumas contribuições nessa área de ensino.

Juntamente com a crítica a respeito dos currículos ditos tradicionais, é crescente o número de propostas de introdução dos tópicos da FMC nos ambientes escolares, tentando consubstanciar uma visão de que ela é importante por diversos motivos (inclusive epistemológicos) e que, além disso, são viáveis de ser abordada no Ensino Médio brasileiro. Nessa perspectiva, o presente texto pretende: i) fazer uma breve revisão da literatura; ii) discutir algumas características epistemológicas do currículo (tradicional em específico); e iiii) apontar um possível caminho de trabalho (conceitual e metodológico) que possibilite a construção de esquemas conceituais capazes de, por sua vez, facilitar ou possibilitar a assimilação de conteúdos Modernos e Contemporâneos da física (VERGNAUD, 1990).

Com base na discussão da literatura e na interpretação dos referenciais adotados, elaboramos um constructo teórico (uma sistemática) que nos ajudará a argumentar acerca das possibilidades práticas e dos desafios de ensino-aprendizagem de determinado tópico de física (nesse caso o do Eletromagnetismo), seja ele tradicional ou não. Em seguida, a 
proposta é elaborar/propor especificamente uma sequência didática potencialmente capaz de amarrar e construir caminhos conceituais que possibilitem a introdução de conteúdos da FMC na educação básica por um caminho que considera o caráter conceitual, didático e metodológico. Conceitual no sentido da necessidade de delimitação epistemológica central a ser abordada, desprendendo-se (em alguma medida) do tradicionalismo; didático, afirmando a necessidade de uma criteriosa, mas criativa, transposição didática do saber científico; e metodológico por indicar uma possibilidade prática para a docência, mesmo que a proposta não seja rígida e impossibilitadora do uso paralelo de outras metodologias.

\section{BREVE REVISÃo BIbliográficA ACERCA DA PESQUisA EM FMC}

Muitos autores nacionais e internacionais dedicaram-se a questionar e expor problemas nos currículos escolares tradicionais de ciências, e em especial os de física, como, por exemplo, em respeito à negligência ou secundarismo dado às teorias e problemas mais recentes desse ramo do conhecimento. Como é enfatizado por Forato (2009), nas últimas décadas, a FMC vem sendo inserida nos programas escolares, mas ainda é pouco ou quase nenhum o papel desses tópicos em comparação aos conteúdos clássicos-tradicionais.

Discutindo acerca dos currículos do Ensino Médio brasileiro, Terrazan (1992) afirma que eles, em sua época, trazem de maneira pobre e tradicional um recorte da física com temas, como Mecânica, Física Térmica, Ondas, Óptica e Eletromagnetismo, concentrando-se em tópicos clássicos (desenvolvidos aproximadamente entre os anos 1600 e 1850).

Infelizmente, não encontramos justificativas, ao menos explícitas, para essa divisão. Na verdade, ocorre que até o momento continuamos a seguir a mesma sequência ditada pelos manuais estrangeiros de ensino de física utilizados no século passado. Dessa forma, as variações em torno dessa divisão, eventualmente adotadas no ensino da física em nossas escolas de $2 z ̌$ grau, são sempre pequenas e mantêm excluída, na prática, toda a física desenvolvida neste século.

(TERRAZAN, 1992, p. 209)

O autor faz constatações acerca do estado educacional em que os conteúdos tradicionalmente abordados em sala de aula não chegam, mesmo que minimamente, na física do século XX e menos ainda na do século atual. Constata, ainda, que o padrão escolar ocupa-se em cumprir um manual vigente (ou paradigma) sem ao menos especular os porquês de se dedicar tanto tempo e esforço nos mesmos conteúdos clássicos em detrimento de conteúdos modernos.

Nesse contexto, mais à frente, argumentamos em defesa da tese de que, para determinados propósitos, poder-se-ia (sem muitos problemas), em um currículo ou sequência didática, abandonar (ou negligenciar) parte dos conteúdos tradicionais recorrentes, para assim abrir espaço e mitigar esforços desnecessários com aqueles que não se ligam essencialmente à estrutura do Campo Conceitual que se deseja ensinar que, no caso desse texto, será o Eletromagnetismo de Maxwell. Focaremos, neste estudo, em analisar uma possibilidade de transição da física clássica para a FMC no interior de uma mesma sequência didática. 
Terrazzan (1992) expõe um argumento em favor da inserção desses conteúdos de FMC no Ensino Médio:

\begin{abstract}
Aparelhos e artefatos atuais, bem como fenômenos cotidianos em uma quantidade muito grande, somente são compreendidos se alguns conceitos estabelecidos a partir da virada deste século forem utilizados [...] No mundo complexo em que vivemos, industrializado e informatizado, a física desempenha papel privilegiado ao fornecer instrumental extremamente importante para essa compreensão.

(TERRAZZAN, 1992, p. 210)
\end{abstract}

Argumenta-se ainda que uma série de problemas de compreensões (de ordem epistemológicas) podem derivar-se justamente da falta desses conteúdos: como a crença de que a física está terminada, ou que não haja ainda atualmente um desenvolvimento dessa ciência, o que representa uma visão distante, incompleta, inconsistente e até errônea do próprio saber científico, indicando, por fim, a perda de coerência no processo de ensino-aprendizagem.

No texto de Ostermann e Moreira (2000), há a análise de uma grande quantidade de trabalhos com argumentos que vão desde a motivação dos estudantes (WILSON, 1992) e (SWINBANK, 1992), da compreensão do mundo tecnológico atual (PEREIRA, 1997) e (VALADARES; MOREIRA, 1998), e a compreensão de questões filosóficas do século XX, como Carvalho et al. (1999) defendem.

Ao assumirmos a necessidade de dar passos em direção aos tópicos modernos e contemporâneos, encontramos uma outra problemática: como inserir de maneira conexa os temas de FMC no currículo, e como tornar viável a sua abordagem em sala de aula?

Os autores supracitados também identificaram, em sua revisão, três principais vertentes de abordagens da FMC no Ensino Médio:

Grosso modo, têm sido consideradas três vertentes representativas de abordagens metodológicas para a introdução de FMC no ensino médio: exploração dos limites dos modelos clássicos; não utilização de referências aos modelos clássicos; escolha de tópicos essenciais.

(OSTERMANN; MOREIRA, 2016, p. 27)

Pontuamos que, em respeito ao caráter da nossa proposta e de suas bases teóricas, inspiramo-nos e ou classificamo-nos como parte da terceira vertente citada anteriormente. Durante o texto, buscaremos construir argumentos teóricos que nos aproximarão em alguma medida dessa vertente, não cabendo no escopo do presente artigo uma discussão acerca dos limites dessa categorização. Contudo, a intenção de nos colocarmos incluídos na categoria de escolha dos tópicos essenciais (OSTERMANN; MOREIRA, 2016, p. 28) advém justamente da visão aqui adotada de que, para construir uma via de acesso à FMC, deve-se fazê-lo através de conceitos essenciais, que serão encontrados na literatura e apoiados pela análise do Campo Conceitual (VERGNAUD, 1990). Busca-se assim, percorrer o caminho conceitual que passa pela física clássica (ou aspectos anteriores), preparando o pano de fundo para a Física Quântica e a Relatividade. 
Exporemos o porquê e quais são exatamente os ganchos conceituais - ou subsunçores - escolhidos aqui para a introdução de tópicos de FMC. Porém, comentaremos primeiro a Teoria dos Campos Conceituais de Vergnaud, que contribuirá justamente para a fundamentação teórica de nossa análise (e escolha) dos elementos conceituais necessários para estruturar-se uma representação significativa do Campo (Conceitual) da Física pré-Moderna/Contemporânea por parte de um estudante.

\section{Campos conceituais de Vergnaud}

A teoria dos Campos Conceituais é uma teoria cognitivista (neopiagetiana) que estuda o desenvolvimento cognitivo (de aprendizagem) dos saberes tidos como complexos, como o técnico e científico. Vergnaud focaliza sua pesquisa no sujeito-em-ação, no funcionamento cognitivo do indivíduo frente a um conteúdo de determinada área do conhecimento, estabelecendo com clareza que as dificuldades de aprendizagem estão ligadas intrinsecamente às especificidades de cada aluno e Campo. Parece-lhe claro que as dificuldades dos estudantes não são as mesmas de um campo conceitual para outro (VERGNAUD, 1996, p. 10 apud MOREIRA, 2002, p. 7). Isso nos indica algo que devemos ter em mente em relação ao processo de ensino-aprendizagem e no momento de uma proposição curricular ou sequência de ensino: a necessidade de considerar as características e a complexidade de cada subcampo conceitual que culmina na consolidação da compreensão de uma determinada área, como a física. Recolocamos a crítica aos materiais e práticas tradicionais que, em muitas vezes, apresentam conteúdos seccionados, mutilados, que se apresentam como fim em si mesmos, prejudicando uma compreensão honesta do Campo.

A premissa dessa teoria é de que o conhecimento se organiza em campos conceituais, que é o conjunto informal e heterogêneo de problemas, situações, conceitos, relações, estruturas, conteúdos e operações de pensamentos entrelaçados no seu processo de aquisição (VERGNAUD, 1990).

O cerne do desenvolvimento cognitivo é então a conceitualização. Por essa perspectiva teórica, Vergnaud intenta compreender o processo de domínio de conceitos, teoremas, da linguagem e simbologia, sendo capaz de operar eficazmente (agir, pensar) nas devidas situações escolares, científicas etc. (Idem).

O campo conceitual é um conjunto de situações/problemas que necessitam de conceitos, procedimentos e representações (de diversas naturezas) que os trate intra-relacionalmente (Idem). O conceito é o conjunto de: situações (que lhe dão sentido), de invariantes operatórios (objetos, propriedades e relações necessários para tratar as situações), e representações simbólicas (linguagem que representa os invariantes operatórios). Assim destacamos a seguinte frase: Mas se os conceitos se tornam significativos através de situações decorre, naturalmente, que as situações e não os conceitos constituem a principal entrada de um campo conceitual. (VERGNAUD, 1998 apud MOREIRA, 2002, p. 11).

Esse detalhe é importante, pois proporemos aqui uma série de situações que possibilitem a entrada no campo da FMC no Ensino Básico. As situações são o que tornam um conceito significativo, que moldam a maneira como é compreendido determinado assunto. Para Vergnaud, o professor tem um papel mediador essencial, que buscará no fundo, apresentar uma quantidade de situações possíveis e necessárias para tornar conceitos e proposição 
significativas. O sentido, que é constituído pelos esquemas incitados por uma situação (ou significante) para lidar com ela. Por fim, podemos compreender um ponto chave: o aprendizado se estabelece ou necessita de uma série de situações que permitam a criação de esquemas que, por sua vez, carregam os conceitos e tornam possível a compreensão de um determinado campo teórico, como, por exemplo, a física moderna.

Vale ressaltar que desejamos retomar e esclarecer o comentário de que o presente trabalho se encontra na vertente que opta por escolher os tópicos essenciais de um campo. Quando vemos que a teoria de Vergnaud explicita que conceitos são compostos de situações, invariantes operatórios, e representações simbólicas afirmamos então que podemos saltar determinadas partes do currículos tradicional, caso a intenção seja traçar um caminho melhor elaborado aos conceitos de FMC, pelo argumento de que, nesse caso, necessitar-se-á de algumas situações, determinados invariantes operatórios e representações simbólicas que sejam capazes de tornarem-se esquemas explicativos do campo (conceitual) da FMC. Cabe ressaltar que, neste processo, o caminho torna-se significante não apenas dos conceitos da FMC, mas também dos elementos clássicos que lhe abriram caminho, de modo que não se descura, neste processo, da concreta apreensão também destes elementos.

Ou seja, o que pretendemos é adotar uma estratégia ou um método de engenharia reversa, que nos permitirá selecionar ou delimitar situações científicas importantes, capazes de operar como uma rota histórica, ou de situações históricas, capazes de ser ou ligar-se a situações que sejam suficientes para tornar significativo os conceitos acerca do conhecimento físico (científico). Já que o desafio aqui trata da introdução da FMC, falaremos em seguida das escolhas conceituais feitas para uma atuação nesse sentido.

\section{Asserções a RESPEITo dA FÍsica PRÉ-MOdERNA E UMA PROPOSTA DE ABORDAGEM}

Alguns trabalhos que tratam da evolução conceitual da física, geralmente narram que a Relatividade e a Física Quântica são provenientes de um contexto conflituoso do final do século XIX, postos, por um lado, pelas controvérsias entre Óptica e Eletromagnetismo, e pelo outro, das diatribes envolvendo a Termodinâmica e a Mecânica estatística.

Polito (2016, p. 145) afirma que

No caso da relatividade especial, a mecânica teve que ceder, e o resultado foi que a metafísica do contínuo, veiculada e articulada pelo conceito de campo, adentrou definitivamente o seu reino. No caso da física quântica, é possível dizer que ocorreu exatamente o oposto. Dessa vez, foi o eletromagnetismo que teve que ceder, e o resultado foi sua invasão por parte da metafísica do discreto, veiculada e articulada pelo atomismo.

Mais à frente, o autor complementa:

Contudo, a síntese operada entre o discreto e o contínuo ainda estava incompleta. Para colocar de modo definitivo, os conceitos de campo e de energia 
(e demais quantidades conservadas) na base de todos os desenvolvimentos posteriores da física, foi necessário realizar o casamento entre relatividade especial e a mecânica quântica. Desse casamento, surgiu a moderna teoria de campos e partículas, até o presente momento, a nossa melhor e mais bem sucedida teoria da realidade.

O ponto que queremos levantar é o fato de conseguirmos conectar a situação históricaconceitual da teoria de partículas por meio de uma narrativa, que parte de uma outra situação histórica-conceitual: do estabelecimento/unificação de dois grandes ramos, a relatividade e física quântica, que por sua vez são estabelecidos enquanto superação de controvérsias entre as teorias clássicas da ótica e eletromagnetismo, e da mecânica e termodinâmica. Se colocado o contexto histórico como coluna dorsal, trazendo situações por meio do contexto, capazes de compor os principais argumentos e teorias da época, seus invariantes operatórios (que no nosso caso serão colocados por intermédio de experimentos importantes), acionando também a linguagem matemática (Representação Simbólica) requerida/conveniente.

Nossa tentativa é expor o caráter de situação no sentido da teoria de campos conceituais que a história da ciência tem, permitindo elencar, de maneira conveniente e adequada, os elementos de um Campo para uma transposição didática que respeite, epistemologicamente, o conhecimento em questão, tendo a vantagem de selecionar as situações históricas pertinentes para a estruturação do trabalho pedagógico. Assim, pensando no contexto escolar, como poderia chegar-se tão longe conceitualmente? Argumentamos que se poderia chegar longe conceitualmente, como no caso da FMC, delimitando onde se quer chegar conceitualmente, e então traçar um caminho, desenvolver uma narrativa que se ramificará o suficiente para possibilitar as situações necessárias para a construção de uma representação significativa por meio da compreensão das controvérsias teóricas entre o Eletromagnetismo e a Teoria Cinética dos Gases, no caso da Mecânica Quântica, e das inconsistências internas, no caso do Eletromagnetismo.

De fato, o século XIX pode ser considerado o século em que foram formuladas duas grandes teorias físicas: por um lado, o Eletromagnetismo surgiu como unificador dos fenômenos elétricos, magnéticos e ópticos. Para tanto, porém, precisou assumir um compromisso ontológico com a existência do éter luminífero, capaz de suportar a propagação da onda luminosa transversal inserida na teoria pelos conceitos fundamentais de campo elétrico e campo magnético. Por outro lado, foi desenvolvida ao longo de todo o século XIX, a Teoria Cinética dos Gases, tributária de uma interpretação atomista da matéria. Interpretação que só se sustenta a partir da assunção da constituição do espaço como um vazio.

Assim, o século XIX criou, em seu bojo, uma contradição interna na física, de caráter ontológico, ao constatar que dois campos conceituais distintos, Eletromagnetismo e Teoria Cinética dos Gases, demandavam constituições diversas (e contraditórias) entre suas noções de espaço (como um plenum formado pelo éter luminífero, ou um vazio).

Tal contradição interna poderia ter se mantido aceitável, ainda que inconveniente, se fosse possível manter os dois campos isolados. Mas a física é um sistema, e sua interconexão foi materializada nos experimentos de espectrometria, justamente aqueles que implicam uma interação entre a matéria e os campos eletromagnéticos. Ao colocar em contato essas duas teorias e, por conseguinte, seus pressupostos ontológicos, os experimentos de espectroscopia 
passaram a exigir uma solução de continuidade, que se concretiza, precisamente, naquele que é o elemento conceitual fundante da Mecânica Quântica, a saber, o Princípio de Dualidade Onda-Partícula. Tal seria o caminho em que conceitos clássicos prévios exigem uma abertura para a concepção quântica do mundo. Note-se que não há supressão das duas perspectivas, mas precisamente uma solução de continuidade que se consubstancia no Princípio de Dualidade, e recebe validação no Princípio de Complementaridade.

No campo especificamente do Eletromagnetismo, nas suas conexões com a Teoria da Relatividade, há também uma dissonância importante, mas não uma contradição em termos, uma vez que as concepções de campo e de corpúsculo são postas em contato. Neste caso, a exigência de um éter luminífero contrasta com exigências que o próprio Eletromagnetismo impunha a tal meio material, demandando dele características opostas entre si, como ser pouquíssimo denso e, ao mesmo tempo, duro. Aqui trata-se de uma contradição interna da teoria, diferentemente da que apresentamos anteriormente, que é uma contradição entre teorias. Os modos de solução da contradição são de caráter diferente neste caso e no anterior.

Neste sentido, a resolução da contradição interna se dá pela imposição, por Einstein, dos princípios da Relatividade Restrita, que suprimem a noção de éter, em favor de uma reconceituação da noção de espaço e tempo.

Assim, uma maneira de introduzir a relatividade no ensino básico seria traçar uma trajetória desses conceitos essenciais, de maneira que uma sequência didática dê conta de pôr estudante razoavelmente a par da questão científica desse período, das motivações que a instigaram, ao mesmo tempo que explicita quais conceitos e ideias são importantes para o surgimento da FMC, aqui identificada com a Teoria da Relatividade Especial.

\section{Estratégia Metodológica}

Baseado na Teoria de Campos Conceituais (VERGNAUD, 1990), pretende-se identificar na literatura conceitos fundantes e constitutivos da física pré-moderna, isto é, aqueles que foram essenciais para que germinasse a FMC. Propor também, baseado na teoria de Campos Conceituais de Vergnaud que se podem fazer pontes, saltos conceituais, no intuito de evitar a demasiada preocupação com conteúdos periféricos, e, no caso específico deste trabalho, indicar um caminho conceitual a percorrer a Física Clássica por meio de uma sequência de investigação como maneira de elencar os elementos conceituais necessários à compreensão da FMC. Nesse caso, propomos uma sequência didática de sete aulas (cada uma de 50 minutos) partindo da ideia de que as equações de Maxwell resumem e centralizam a teoria eletromagnética, e que, tanto a demonstração experimental, quanto a exposição dos embates históricos-conceituais (como sobre a própria existência do éter) permitem a formação de esquemas (idem) acerca do eletromagnetismo necessários à compreensão da relatividade especial.

\section{V.1. Proposta de uma Sequência Investigativa}

O eletromagnetismo, diferentemente da mecânica, é diversas vezes abstrato para os alunos, de maneira que alguns conceitos, básicos ou complexos, não são fixados efetivamente 
por falta de modelos que os alunos possam associar ao seu cotidiano, ou algum conhecimento prévio, o que dificulta o aprendizado.

Para se ter maior clareza no entendimento e melhor visualização de fenômenos, a utilização de experimentos na sala de aula é valiosa. O conteúdo que é visto pelos estudantes do terceiro ano do Ensino Médio é abstrato, ainda que seus resultados sejam totalmente passíveis de visualização a partir de exemplos do cotidiano. Alguns conceitos como carga, campos elétricos e magnéticos, diferença de potencial, trabalho de uma força elétrica entre outros, não são palpáveis para o aluno. Uma das soluções para esse problema é a utilização de experimentos. Higa e Oliveira (2012), ao analisarem diversos artigos, observaram que, em um nível epistemológico-pedagógico, a experimentação tem diferentes abordagens em suas propostas.

Metodologicamente, algumas são mais demonstrativas, priorizando, sobretudo, a observação, e outras são mais de atuação por parte do estudante, priorizando a investigação. [...] três artigos tratam de atividades do tipo demonstrativas, sendo que seus autores enfatizam a importância das interações sociais no seu desenvolvimento, e quatro enfocam as atividades como situações investigativas. Alguns envolvem uso de computador para registro de dados ou acontecem apenas em forma de resolução de problemas nos textos-roteiros e há atividades que são desencadeadas a partir da aplicação de um questionário para levantar as concepções prévias dos estudantes. Tais abordagens são derivadas do referencial teórico adotado pelos autores. Há aqueles que se amparam em uma perspectiva sociointeracionista, como Vygotsky e seus seguidores, alguns poucos em uma vertente mais construtivista cognitivista, como Piaget, ou ainda mais cultural, como Paulo Freire e também numa perspectiva psicanalítica. (HIGA, OLIVEIRA, 2012, p. 83)

A maneira como a experimentação é introduzida no plano de aula pode ser adaptada, considerando que existem diversos objetivos e abordagens. $\mathrm{O}$ experimento de Oersted, por exemplo, viabiliza a utilização de vários conceitos do eletromagnetismo, relembra ideias de eletricidade, inicia as ideias de magnetismo e une os dois conceitos. A partir disso, podem se iniciar os estudos a respeito de magnetismo, partindo da aplicação do experimental adequado que se enfatize a união dos dois conceitos, o elétrico e magnético, para que se tenha uma aprendizagem relevante e apropriada, indicando, por exemplo, a unificação da própria Ótica.

Os alunos que ainda não obtiveram conhecimentos acerca da unificação das duas teorias sobre magnetismo e eletricidade sentirão uma grande dificuldade e essa constatação não é simples ou óbvia, mas a verdade é que a compreensão da radiação como evento eletromagnético, em particular, é crucial para a compreensão do próprio eletromagnetismo em geral.

Um desafio que o professor encontra ao inserir a parte histórica da ciência é a ausência de conhecimento aprofundado da história. Os livros didáticos geralmente tratam do assunto de maneira rasa, como uma parte opcional de leitura, destacado do restante do assunto, em que é difícil se fazer conexão com a teoria e os cálculos do tema. Quando o foco está na resolução de exercícios, a física se torna uma matemática aplicada, um formulismo 
banalizador, com pouco espaço para discussão de fenômenos, sem conexão com a história e com o cotidiano.

Reservar uma aula para conversar com os alunos acerca desses cientistas e de suas descobertas em um contexto educacional torna-se apropriado quando se objetiva expandir o entendimento do aluno a respeito do conteúdo físico, dos dilemas filosóficos e demais aspectos humanos, indo além das equações matemáticas, em direção a uma sociologia do conhecimento, que expande a dimensão meramente epistemológica. Além disso, a prática favorece o envolvimento dos alunos que se identificam mais com as ciências humanas.

Assim, é proposta uma sequência didática que envolva o aluno com a percepção de que os fenômenos elétricos e magnéticos têm relações conhecidas, e que, além disso, a unificação desses ramos permitiu a formulação de uma teoria que avançou até um ponto em que suas questões produziram uma reconceituação no ramo da física, algumas vezes implicando mesmo em ruptura ${ }^{1}$. Para isso, é preciso que o aluno entenda primeiro os fundamentos acerca dos fenômenos elétricos e magnéticos para então introduzirmos o estudo da Física Moderna.

\section{V.2. O desenvolvimento da sequência}

A Sequência Didática (SD) proposta a seguir foi aplicada em uma turma de 3ř ano do Ensino Médio do Colégio Estadual José de Assis na cidade de Santo Antônio do Descoberto - Goiás. A SD proposta, originalmente pensada com base no referencial teórico, tem duração de nove aulas de 50 minutos. Porém, dada as dificuldades práticas de aplicação, foram realizadas algumas alterações: as aulas 3 e 4 foram abordadas fora da ordem proposta, e uma aula teve de ser suprimida.

\section{V.3. Detalhamento das atividades}

A seguir, detalharemos cada aula a partir dos seguintes aspectos: problema central da aula, objetivos principais e específicos, duração da atividade, tópicos de física, conhecimentos prévios, estratégias, vinculação teórica, vinculação metodológica e avaliação.

\section{V.3.1 AULA 1 - Introdução Histórica/Conceitual}

a) Problema- Motivar os alunos ao estudo do eletromagnetismo como meio de compreender parte da Física Moderna.

b) Objetivo principal - Identificar e rememorar os elementos conceituais, situações e esquemas necessários para a compreensão do eletromagnetismo e da FMC por parte dos estudantes.

\footnotetext{
${ }^{1}$ Embora tenhamos empregado aqui este termo, o que a história da física tem evidenciado é que não não houve, da perspectiva kunhiana, uma ruptura entre a Física Clássica (FC) e a Teoria da Relatividade (TR). Houve, podemos afirmar, um reposicionamento conceitual sobre espaço e tempo, e aquilo que disso decorre. A TR continua usando inúmeros construtos da FC, diferentemente da Mecânica Quântica, que, na forma como a interpretamos, implicaria, de fato, em uma ruptura
} 
c) Objetivos específicos - Abordar conceitos já estudados ao longo dos bimestres como o de Campo Elétrico e suas características; apresentar os novos termos que serão inseridos ao longo da Sequência Didática que serão importantes para o estudo da Física Moderna.

d) Tópicos de Física Campo Elétrico, Campo Magnético, Física Moderna

e) Conhecimentos Prévios Os alunos precisarão ter entendimento acerca dos conceitos básicos de campo elétrico e suas características. Esses conhecimentos foram abordados nos bimestres iniciais, visto que o objetivo desta sequência é uma introdução à física moderna, passando pelo eletromagnetismo, explanada apenas no final do ano letivo. Compreender como as características/conceitos estudados anteriormente influenciam no desenvolvimento da série, uma vez que os termos se repetem, como campo elétrico, corrente elétrica, linhas de campo e estendem-se para outros conceitos de que são pré-requisitos.

f) Estratégias A primeira aula desta sequência é uma introdução histórica/conceitual que relembra termos do eletromagnetismo e seus significados, incentivando os alunos no estudo da Teoria Eletromagnética e da Física Moderna, apresentando a estrutura das equações de Maxwell e sua relevância. Esta primeira aula tem duração de 50 minutos, uma hora-aula, e, para sua realização, será usado o livro didático Os alicerces da física 3 Kazuito, Fuke e Carlos. Esse livro é dividido em unidades, e o professor abordará todas as unidades: as três primeiras mais rapidamente, explanando a Eletrostática, na primeira unidade; a Magnetostática na segunda; o Eletromagnetismo na terceira unidade; e, por fim, a quarta é acerca da Física Moderna;

g) Vinculação teórica - Visto que a proposta é construir uma estrutura conceitual com os estudantes por meio da apresentação de um determinado número de situações, cabe identificar/relembrar qual conteúdo conceitual já foi assimilado pelo estudante, além de explicitar quais serão importantes nesse momento.

h) Vinculação metodológica - Esta metodologia facilita a visão da proposta pelos alunos, ou seja, aquilo que eles podem esperar ao longo da Sequência Didática, visto que essa Introdução histórica/conceitual é uma aula que explana alguns conteúdos já vistos e o que eles verão pela frente, em um diálogo com os estudantes. A fala do aluno é de grande importância, pois o professor deverá captar a reação dos alunos para dar continuidade ao assunto da maneira que julgar mais apropriada, selecionando os elementos que eles trazem consigo previamente.

i) Avaliação: Observação da participação dos alunos, considerando os elementos conceituais expostos por eles, como maneira de avaliar a formação inicial de esquemas.

\section{V.3.2 AULA 2 Experimento Lei de Gauss}

a) Problema - Compreensão do esquema teórico da Lei de Gauss por meio de uma situação experimental. 
b) Objetivo principal - Visualizar por meio do experimento realizado, os conceitos estudados a respeito de condutores em equilíbrio eletrostático e a ausência de Campo Elétrico no interior de uma casca esférica (através da Lei de Gauss).

c) Objetivos Específicos - Relembrar a teoria estudada previamente.

d) Tópicos de Física - Equilíbrio eletrostático, distribuição das cargas em um material condutor e blindagem eletrostática.

e) Conhecimentos Prévios Nesta atividade, os alunos precisarão compreender as propriedades do Campo Elétrico, especificamente em condutores em equilíbrio eletrostático. Este conteúdo foi visto anteriormente com suas devidas equações e rigor teórico e relembrado na última aula, juntamente com a introdução histórica/conceitual em que foi abordada a propriedade do Campo Elétrico. O entendimento da característica do campo E implica em um bom desenvolvimento da aula, mas não privará os alunos que ainda não assimilaram a teoria da Lei de Gauss. Esta aula facilitará a visualização desse conteúdo, ou seja, o aluno que percebeu que dentro de uma casca esférica condutora não há campo elétrico, irá prever o resultado do experimento. Entretanto, o aluno que não compreendeu essa propriedade do campo E ao longo das aulas teóricas, o visualizará por meio do experimento demonstrativo.

f) Estratégias Para esta aula de experimento demonstrativo, de duração de 50 minutos, será relembrado o equilíbrio eletrostático de um material condutor, a distribuição das cargas elétricas e a blindagem eletrostática que será demonstrada por meio de um experimento; exemplos, como a explicação do por que o motorista de um carro atingido por um raio não é eletrocutado? - a gaiola de Faraday , farão uso do livro com imagens. Em seguida, apresentar um experimento usando dois celulares e um papel alumínio da seguinte maneira: fazer uma ligação de telefone entre os alunos; eles deverão visualizar o telefonema e o celular em funcionamento perfeito, em seguida o professor deverá questionar o que acontece se o celular receptor da ligação estiver envolto em um papel alumínio. Os alunos deverão discutir entre si acerca da resposta e justificar a sua conclusão antes de testar a nova ligação. Assim que os alunos experimentarem novamente a ligação com o celular envolto em um papel alumínio, deverão perceber a blindagem eletrostática juntamente com a Lei de Gauss.

g) Vinculação teórica - a realização experimental demonstrativa pode compreender-se como uma apresentação de situação no sentido da teoria de campos conceituais ${ }^{2}$.

h) Vinculação metodológica - Experimento de fácil reprodução e visualização.

\section{V.3.3 AULA 3 Aula teórica a respeito do Campo Elétrico}

a) Problema - Necessidade de formulação teórica necessária para explicar o fenômeno exposto na aula anterior.

\footnotetext{
${ }^{2}$ Em um contexto de experimentação investigativa, poder-se-ia inverter a ordem. Realizar primeiramente o experimento com os celulares, usando alumínio em um caso e um pano comum em outro, e procurar, por investigação, o estabelecimento de hipóteses, etc, que representam o fazer científico investigativo.
} 
b) Objetivo principal - Compreender a Lei de Gauss demonstrando a relação entre o Campo Elétrico e a blindagem eletrostática.

c) Objetivos Específicos - Relacionar os conceitos abordados em aulas anteriores com a aula experimental e finalizar o assunto; recuperar possíveis dificuldades dos alunos; relacionar a característica das ondas eletromagnéticas com o resultado visto no experimento em que a ligação não foi possível de ser concluída

d) Tópicos de Física - Campo Elétrico, blindagem eletrostática e ondas eletromagnéticas.

e) Conhecimentos Prévios Características de um Campo Elétrico E, e blindagem eletrostática.

f) Estratégias Esta aula tem duração de 50 minutos e deverá ser iniciada retomando o experimento da blindagem eletrostática. No caso de disponibilidade de aula dupla, pode-se realizar o experimento e prosseguir com essa atividade proposta na mesma sequência. O professor deverá fazer uma ligação entre a propriedade do Campo Elétrico na blindagem eletrostática e o porquê de o celular receptor da ligação não responder após ser envolvido no papel alumínio. O conceito de ondas eletromagnéticas deverá ser abordado de maneira que os alunos compreendam as características dessas ondas. Neste contexto, a caracterização das ondas eletromagnéticas como ondas transversais, indutoras da dificuldade relativa à constituição do éter, deve ser enfatizada.

g) Vinculação teórica - A compreensão de que o fluxo do campo elétrico se anula nesse caso demonstra parte da estrutura conceitual das equações de Maxwell, o que ajudará a sintetizar o eletromagnetismo.

h) Vinculação metodológica - a presente aula expositiva cumpre o papel de apresentar os conceitos e a formulação em uma linguagem mais técnica, rigorosa, controlada.

\section{V.3.4 AULA 4 Aula Teórica Campo Magnético}

a) Problema - Definição do Campo Magnético na estrutura teórica.

b) Objetivo principal - Apresentar o Campo Magnético e suas características em materiais.

c) Objetivos Específicos - Progredir da compreensão do senso comum, das experiências cotidianas com imãs para a formulação científica.

d) Tópicos de Física Imã, propriedades do ímã, Campo Magnético - B do imã e da Terra.

e) Conhecimentos prévios $\mathrm{O}$ aluno precisa compreender o comportamento de um imã na presença de outro e na presença de um material feito de ferro; entender o comportamento de uma bússola; não necessariamente saber o motivo do seu comportamento, que será abordado pelo professor em sala de aula.

f) Estratégias - Os alunos terão em mãos o livro didático no capítulo que se introduz o Campo Magnético e o professor dará uma aula expositiva com auxílio do livro, das 
considerações e ideias dos alunos e, dessa maneira, a aula será conduzida no ritmo dos alunos sem muito rigor formal ainda. A ideia é que os alunos tenham noção de Campo Magnético, relativamente a curiosidades, como, por exemplo, a aurora boreal e porque ela existe, como uma bússola funciona e o porquê. Esta aula tem duração de 50 minutos. Caso o professor perceba que uma aula não será suficiente para desenvolver o conteúdo, é interessante que se estenda para mais uma aula e só então essa sequência avance para a aula experimental.

g) Vinculação teórica - Dada a dificuldade e dispensabilidade de profundidade matemática, a compreensão conceitual de forma ampla do que é o campo magnético (ainda separado do elétrico) contribuirá para o momento em que (na SD) explicar-se-á como se produz um campo magnético, e sua relação com o elétrico.

h) Vinculação metodológica - o magnetismo, de certa forma, já é conhecido pelos estudantes, que já carregam esquemas provenientes de saberes populares, cotidianos. O uso do livro didático auxiliará elencando determinados problemas, perguntas motivadoras que instigam a reflexão acerca da natureza magnética, e da produção do campo B que, em seguida, poderá ser explicada unificando-a com os fenômenos elétricos.

\section{V.3.5 AULA 5 - Experimento Monopolo Magnético}

a) Problema- Distinguir os Campos Magnético e Elétrico.

b) Objetivo principal - Demonstrar experimentalmente semelhanças e diferenças entre os campos elétricos e magnéticos.

c) Objetivos Específicos - Montar um experimento para a visualização das linhas de Campo Magnético; observação das linhas de campo e diferenciar das linhas de Campo Elétrico.

d) Tópicos de Física Linhas de Campo Magnético de um imã e da Terra.

e) Conhecimentos prévios Os alunos deverão ter entendimento acerca do Campo Magnético e sua configuração de linhas; sua diferença com as linhas de campo de uma carga elétrica; linhas de Campo Magnético da Terra para entendimento e melhor confecção de uma bússola.

f) Estratégias Nesta aula, os alunos terão acesso a um kit que inclui folhas brancas, imãs e limalhas de ferro. Para isso, o professor deverá dividir a turma da melhor forma, questão que depende da quantidade de kits disponíveis para a turma. Se a quantidade de materiais existentes for suficiente para formar apenas um kit, isso não será um problema, pois a qualidade do experimento, por ser demonstrativo, não implicará em prejuízo. Após o professor relembrar aos alunos acerca das linhas de campo, o experimento deverá ser realizado; para isso, a montagem do experimento deverá ser feita de maneira que o imã ficará embaixo da folha de papel branca e as limalhas de ferro serão distribuídas na folha o mais homogeneamente possível. Dessa forma, os alunos observarão as linhas de campo magnético na folha e como as limalhas se distribuirão, de maneira que visualizem a característica das linhas de campo magnético que são diferentes das linhas do campo 
elétrico, verificando a ausência de monopolo, dado que as linhas de campo se fecham nos polos do ímã. Para finalizar a aula, o professor deverá comentar essas diferenças elétricas e magnéticas, incluindo a Terra e seu campo magnético detectável.

g) Vinculação teórica - A compreensão de que o fluxo do campo magnético difere do elétrico demonstra parte da estrutura conceitual das equações de Maxwell, o que ajudará a sintetizar o eletromagnetismo.

h) Vinculação metodológica - a realização experimental demonstrativa pode compreenderse como uma apresentação de situação no sentido da teoria de campos conceituais.

\section{V.3.6 AULA 6 - Experimento- Eletroímã}

a) Problema- Aplicar a Lei de Ampère, demonstrar relação entre eletricidade e magnetismo.

b) Objetivo principal - Compreender as propriedades magnéticas em um material de ferro enquanto há corrente magnética em volta.

c) Objetivos Específicos - Realizar um experimento montando um eletroímã para demonstrar a Lei de Ampére; observar a intensidade do Campo Magnético devido ao número de voltas do solenoide montado; perceber que com a corrente elétrica o material de ferro corresponde a um ímã temporário e que, sem a corrente elétrica no fio condutor, o ferro deixa de ter propriedades magnéticas.

d) Tópicos de Física - Corrente elétrica e Campo Magnético devido a um solenoide.

e) Conhecimentos prévios - Campo Magnético gerado por uma corrente elétrica em um fio condutor. Saber que o Campo Magnético em um solenoide é mais intenso que um fio reto ou em formato de espira.

f) Estratégias - Os alunos estarão dispostos em grupos de até quatro pessoas e trarão para a sala de aula os materiais para a realização do experimento, como um prego, uma pilha de 1,5 V, fio condutor e um material de ferro ou níquel como, por exemplo, grampos ou moedas para serem atraídos. Os alunos terão o horário de uma aula de 50 minutos para a montagem e execução do experimento; irão montar um eletroímã e deverão comentar com o professor a respeito do que foi observado: se a quantidade de voltas de fio no prego (material de ferro) influencia na intensidade do Campo Magnético.

g) Vinculação teórica - a unificação entre eletricidade e magnetismo é um dos pontos altos da teoria. Foi um dos grandes feitos dos físicos, incluindo Maxwell, que proporá um éter mecânico capaz de explicar (parcialmente) os fenômenos ópticos, elétricos e magnéticos. O curso de eletricidade e magnetismo começa a encaminhar-se à controvérsia que produzirá a relatividade especial.

h) Vinculação metodológica - a utilização de um experimento interativo possibilita que os próprios estudantes procurem uma explicação ao fenômeno. A percepção de que os fenômenos elétricos e magnéticos são relacionáveis é um ponto essencial da teoria. A visualização concreta é, a princípio, uma situação bastante rica. 


\section{V.3.7 AULA 7 Aula teórica Lei de Ampére}

a) Problema- Apresentar o Campo Magnético gerado por um fio condutor com corrente elétrica sendo um fio retilíneo, espiral ou um solenoide.

b) Objetivo principal - Demonstrar a possibilidade de um campo magnético ser criado por meio de variações na corrente elétrica.

c) Objetivos Específicos Por meio do livro didático, tratar sobre o campo magnético gerado por um fio condutor.

d) Tópicos de Física Corrente elétrica em um fio condutor e campo magnético.

e) Conhecimentos Prévios Corrente elétrica em um fio condutor e o Campo Magnético.

f) Estratégias Para esta aula, o professor deve abordar o campo magnético gerado por um fio condutor e suas diferentes intensidades devido ao seu formato, demonstrado por meio das equações para cada formato.

g) Vinculação teórica - a unificação entre eletricidade e magnetismo é um dos pontos altos da teoria. Foi um dos grandes feitos dos físicos, incluindo Maxwell, que propôs um éter mecânico capaz de explicar (parcialmente) os fenômenos ópticos, elétricos e magnéticos. O curso de eletricidade e magnetismo começa a encaminhar-se à controvérsia que produzirá a relatividade especial.

h) Vinculação metodológica - para que o estudante seja capaz de sintetizar com rigor a teoria, atentando-se aos aspectos conceituais centrais que poderão ser requisitados em uma próxima aula de introdução à FMC, faz-se necessário um debate/explanação com/do professor. Todas as situações apresentadas são capazes de produzir um esquema conceitual coerente, mas sempre sujeito a erros, incoerências etc. Assim, o professor como um mediador pode aparar ideias excedentes e preencher lacunas teóricas que restam. Nesse caso, temos insistido que Einstein inicia seu trabalho de Relatividade Especial justamente ao trabalhar em um problema da teoria maxwelliana, em específico, a invariância da velocidade da luz no experimento de Michelson-Morley.

Entendemos que as discussões históricas, conceituais e fenomenológicas nesse ponto elencaram minimamente a estrutura conceitual necessária à abordagem da FMC, em especial, a Relatividade.

\section{Discussão dos Resultados}

A aplicação da SD, realizada em sete encontros, pode ser considerada como uma sequência válida e aplicável, pois contém aspectos que foram avaliados positivamente pelos estudantes. O envolvimento de questões históricas em aulas teóricas e pelos experimentos palpáveis corroboravam o que era estudado teoricamente, fazendo com que os elementos históricos se imiscuam na própria aprendizagem do objeto. 
No primeiro encontro, alguns alunos relembraram dos conteúdos conceituais com mais facilidade que outros; ao longo da aula entenderam e aceitaram a proposta da sequência didática, bem como sua importância para a introdução da Física Moderna. Foi observado que os alunos interagiam entre si para entender como se daria a proposta.

No segundo encontro, os alunos tiveram receio em afirmar se a teoria estudada acerca da existência de campo elétrico dentro de uma casca esférica valeria para o celular envolvido no papel alumínio; após o experimento, os alunos ficaram impressionados, comentaram e discutiram a respeito de algumas aplicações do cotidiano e conseguiram perceber/compreender a blindagem eletrostática juntamente com a Lei de Gauss.

O terceiro encontro foi reservado para o rigor teórico exigido; houve participação dos alunos que sintetizaram o conteúdo visto na aula experimental com a dimensão teórica. Os alunos deram retornos positivos quanto ao conhecimento a que foram expostos.

A quarta aula, também teórica, foi bastante discutida; houve muito espaço para os alunos falarem, e foi observado que eles traziam muitos comentários, inclusive alguns termos equivocados em relação a propriedades dos ímãs e materiais ferromagnéticos, que foram ajustados. A aula foi concluída como esperado, e os alunos participaram e tiraram dúvidas.

No quinto encontro, foi demonstrado por meio de um experimento, as linhas de campo magnético que na aula anterior haviam sido desenhadas no quadro e vistas no livro didático. A aula foi atrativa para os alunos, pois houve participação de todos no manuseio dos materiais e puderam visualizar as linhas de campo magnético.

No sexto encontro, realizamos um experimento e reproduzimos um eletroímã; a sala foi dividida em grupos e isso facilitou a integração entre os alunos. Alguns grupos não conseguiram realizar os experimentos sozinhos, mas outros grupos sim, e eles se ajudaram até que concluíram o experimento e verificaram as propriedades do eletroímã. O grupo que não concluiu o experimento usou material emprestado por outro grupo, pois o problema parecia ser com a pilha utilizada pelos alunos.

Na última aula da sequência, foram abordados teoricamente aspectos da Lei de Ampère e foi feita uma breve introdução a respeito do que seria apresentado a partir dessa sequência; iniciou-se, então, o estudo acerca da Física Moderna Contemporânea. A proposta da sequência didática pretendeu envolver o aluno na percepção do entendimento da unificação dos fenômenos elétricos e magnéticos permitindo, dessa forma, o avanço para o estudo da Física Moderna.

\section{CONSIDERAÇÕES FINAIS}

Em síntese, o que o presente trabalho constatou que é factível, na prática escolar e até curricular, inserir elementos históricos e filosóficos em uma tentativa de tornar o assunto atrativo, complementar, e expor certas características da ciência. É um elemento utilizado em grande parte dos textos que foram revisados para a produção deste trabalho.

Entretanto, o queremos destacar na nossa análise é que existe um motivo bastante razoável para que esses elementos históricos-conceituais funcionem não só como complemento, mas como parte essencial da estrutura de um curso, ou de um currículo, pelo fato de, segundo a Teoria de Campos conceituais, um construto histórico-conceitual atuar como uma situação capaz de produzir esquemas e significado. 
Finalizamos fazendo algumas asserções e provocações. Primeiro afirmando que um dos maiores problemas em abordar a FMC é a falta de construção de uma narrativa única que respeita os conflitos metafísicos, ontológicos e epistemológicos desse saber. Sendo o currículo tradicional criticado por, em geral, segmentar os ramos da física e assim dificultar qualquer tentativa pedagógica de temas que só foram desenvolvidos originalmente pela unificação ou superação de uma visão de mundo.

É necessário que o professor mostre outras possibilidades de ensino: demonstrações com experimentos são oportunidades interessantes que modificam o ambiente, sendo razoável supor que haverá um engajamento maior por parte dos alunos. Para se distanciar de um aprendizado mecânico em que apenas a memorização é valorizada, uma ótima alternativa é a experimentação discutida, pensada e avaliada.

Por fim, defendemos a qualidade dessa sistemática como uma possível resposta às críticas das pobres ou nenhuma abordagem da física modernas e contemporâneas em detrimento do currículo tradicional do ensino médio. Não porque intenta prescrever qual tipo de abordagem seria melhor, se construtivista, humanista etc. (ficando a cargo de cada professor e do curso decidir as abordagens, a considerar seu público e suas condições), mas porque indica uma estratégia apoiada em uma teoria cognitiva de aprendizagem bastante legitimada de como guiar-se na tentativa de abordar um determinado conteúdo de FMC que, dada a sua natureza, requer ser situada em sua historicidade.

\section{REFERÊNCIAS}

FORATO, T. C. de M. A natureza da ciência como saber escolar: um estudo de caso a partir da história da luz. 2009. Tese de Doutorado. Universidade de São Paulo.

HIGA, I.; OLIVEIRA, O. B.. A experimentação nas pesquisas sobre o ensino de Física: fundamentos epistemológicos e pedagógicos. Educar em Revista, n. 44, p. 75-92, 2012.

MOREIRA, M. A. A teoria dos campos conceituais de Vergnaud, o ensino de ciências e a pesquisa nesta área. Investigações em ensino de ciências. Porto Alegre. Vol. 7, n. 1 (jan./mar. 2002), p. 7-29, 2002.

OSTERMANN, F.; MOREIRA, M. Antonio. Uma revisão bibliográfica sobre a área de pesquisa Física Moderna e Contemporânea no Ensino Médio. Investigações em ensino de ciências, v. 5, n. 1, p. 23-48,2000.

et al. Fundamentos da física quântica à luz de um interferômetro virtual de MachZehnder. Revista electrónica de enseñanza de las ciencias. Ourense. Vol. 8, no. 3 (2009), p. 1094-1116, 2009.

POLITO, A. M. M. A construção da estrutura conceitual da física clássica. São Paulo: editora livraria da física, 2016.

TERRAZAN, E. A. A inserção da Física moderna e contemporânea no Ensino da Física na 
Escola de Segundo Grau. Atas da V Reunião Latino Americana de Educação em Física, 1992.

VERGNAUD, G. La teoría de los campos conceptuales. Recherches en didactique des mathématiques, v. 10, n. 2, p. 3, 1990. 